Article

\title{
Investigating Yield Variability and Inefficiency in Rice Production: A Case Study in Central China
}

\author{
Zhihai Yang ${ }^{1, *}$, Amin W. Mugera ${ }^{2}$ and Fan Zhang ${ }^{2,3}$ \\ 1 College of Economics and Management, Huazhong Agricultural University, Wuhan 430070, China \\ 2 School of Agricultural and Resource Economics, The University of Western Australia M089, \\ 35 Stirling Highway, Crawley, WA 6009, Australia; amin.mugera@uwa.edu.au (A.W.M.); \\ fanzhang0124@gmail.com (F.Z.) \\ 3 Centre for Environmental Economics and Policy, The University of Western Australia M089, \\ 35 Stirling Highway, Crawley, WA 6009, Australia \\ * Correspondence: zhyang@mail.hzau.edu.cn; Tel.: +86-27-8728-6896
}

Academic Editor: Hossein Azadi

Received: 1 June 2016; Accepted: 8 August 2016; Published: 11 August 2016

\begin{abstract}
Insufficient and high variability in rice yield is a threat to food security in China, prompting the need for strategies to mitigate yield variability and increase productivity. This study investigates the presence of production risk and technical inefficiency for a sample of rice farms in the Xiangyang city of China using a stochastic production frontier framework. Results from the risk function reveal that labor and better soil quality have significant risk-reducing effects while machinery exerts a significant risk-increasing effect on rice production. The estimated mean technical efficiency score is $84 \%$, suggesting that, on average, farmers could increase their rice production by $16 \%$, without increasing the existing input levels by improving their management techniques. Factors that significantly affect technical efficiency are the age of farmers, female ratio, access and use of extension services, off-farm income, and the size of cultivated land. Results from this study suggest that yield variability and technical inefficiency in rice production can be reduced by appropriate choice of input combinations and elimination of mistakes in the production process through efficient management practices. Strategies, such as providing better extension services, loosening liquidity constraints facing farmers, and expanding rice farmers' producing area, would help to achieve minimum inefficiency in production.
\end{abstract}

Keywords: production risk; technical efficiency; rice farming; stochastic frontier production function; China

\section{Introduction}

Grain is one of the most important sources of human nutrition in many parts of the world [1]. However, with the increasing human population, coupled with the impacts of climate change and environmental degradation, the current grain supply does not keep up with its demand, which is clearly reflected by the global food crisis [2]. Consequently, food insecurity still is a major concern around the world, including China. China's food security has been a major issue of concern for a long time due to its high population ( $22 \%$ of the globe) and scarce cultivated land ( $7 \%$ of the globe) [3].

Over the past few decades, the Chinese government has put much effort into enhancing grain productivity in order to meet food demand for more than one billion residents. China's efforts have largely paid off in terms of increased rice production, from 59 million tons in 1960 to 204 million tons in 2012 [4]. However, high variability in rice production was also observed during the same period. Moreover, it is worth noting that China is the world's largest rice producer, occupying about $28 \%$ of the world's total area under rice production in 2012 and fluctuations in its rice supply have substantial 
influence on the world's grain market [5]. From this perspective, stable grain production in China is of great importance both for domestic and global food security. However, Chinese grain production is facing unprecedented challenges to continue to produce more rice while being constrained by limited arable land, population growth pressure, environmental pollution, degradation of soil fertility, water scarcity, and climate change [6-8]. These problems pose a challenge to the sustainability of agricultural production, especially the country's ability to maintain a high level of crop productivity and stability in the long run [9-11]. Within this context, China's political agenda has always placed a high priority on managing production risk to minimize yield variability and finding methods to motivate farmers to make efficient use of scarce farm resources and, thus, contribute to the growth of productivity.

The food insecurity pressure has prompted significant research efforts to investigate the technical efficiency of agricultural production in China, but with limited empirical studies at the crop level. Among the existing literature, Wang et al. [12], Zhang et al. [13], Brümmer et al. [14], Li and Sicular [15] estimated technical efficiency for the farms in different regions of China at the aggregate agricultural output level, but not on a specific crop. In contrast, Ma et al. [16] investigated the technical efficiency of rice farmers in the Taihu Basin of China and found there is substantial technical inefficiency in production. However, none of these studies took proper account of the presence of production risk and farmers' responses to it, whereas it is common knowledge that economic units make their decisions under high risk and uncertainty.

Grain production is inherently risky resulting in wide variability in yield [17] due to biophysical factors, such as weather, soil, and diseases [18]. The presence of risks not only affect yield but also producers' behavior with regard to input use [19]. Facing the uncertainties in production, farmers will try to mitigate these risks through input choices, since they are generally risk-averse [18]. However, inputs can either increase or reduce the level of output variance (production risk) but this effect is regional, environmental, and situation-specific [20,21]. Therefore, an economic analysis of the relationship between input use and output variance would be useful, not only to farmers through increased knowledge about risk effects of their input choices, but also for policy-makers involved in risk management in the grain industry. Furthermore, if production risk exerts an important influence on a famer's production decision, then the farmer's technical efficiency performance may alter significantly [19]. This suggests that production risk and producer's response need to be incorporated into the empirical models for estimating technical efficiency.

Therefore, the objective of this study is to investigate the factors that drive yield variability and limit farms from achieving maximum potential yields for rice farms in China. This is done within the stochastic production frontier framework that simultaneously estimates both the inefficiency function and risk function. The risk function is used to determine which inputs are risk-increasing (or risk-decreasing) while controlling for soil quality and weather events. The inefficiency function investigates key determinants of technical inefficiency. The focus of the study is on 231 smallholder rice farms in Xiangyang, one of the most important rice producing territories in China. Disentangling the mutual effects of production risk and technical inefficiency on rice yields is important for policy interventions geared towards bridging the yield gap and improving rice productivity. To the best of our knowledge, this is the only study to investigate rice yield variability in the Xiangyang city of China with a focus on the determinants of technical efficiency and production risk.

The rest of the paper is organized as follows: Section 2 describes the methodology and data used to estimate technical efficiency and production risk; the results and discussions are presented in Section 3; and Section 4 draws conclusions and policy implications.

\section{Methodological Framework and Materials}

In this study, we employ a stochastic frontier production function with an additive heteroskedastic error structure to estimate the level of, and factors affecting, production risk and technical efficiencies of rice farms. 


\subsection{Integration of Risk into Stochastic Frontier Analysis}

The stochastic frontier analysis (SFA) is a parametric method of efficiency analysis, which was originally proposed by Aigner et al. [22], and Meeusen and van der Broeck [23]. The stochastic frontier production function has the general form:

$$
y_{i}=f\left(x_{i} ; \beta\right) \exp \left(\varepsilon_{i} \equiv v_{i}-u_{i}\right)
$$

where $y_{i}$ is the output of farm $i(i=1, \ldots, N) ; x_{i}$ represents the input vector; $\beta$ is the parameter vector to be estimated; $\varepsilon_{i}$ is a composed error term consisting of $v_{i}$ and $u_{i}$; of which $v_{i} \sim N\left(0, \sigma_{v}^{2}\right)$ is the random error term intended to capture measurement errors and the random variations in output as a result of factors out of the control of farmers; and $u \sim N\left(0^{+}, \sigma_{u}^{2}\right)$ is a nonnegative and independent error term, representing the shortfall of output from the production frontier.

The output-oriented technical efficiency (TE) is defined as the ratio of observed output to maximum feasible output in the production frontier. The TE of a specific farm is expressed as:

$$
T E_{i}=y_{i} /\left[f\left(x_{i} ; \beta\right) \exp \left(v_{i}\right)\right]
$$

However, this usual specification of the stochastic frontier production function has a disadvantage that may seriously limit its potential to depict production technology appropriately. It implicitly assumes that the positive effect of any inputs on output will simultaneously positively affect the variability of output. Yet, Just and Pope [20] have shown that this assumption is not necessarily tenable in many agricultural circumstances. Instead, they proposed a more general model that includes two functions:

$$
y_{i}=f\left(x_{i} ; \beta\right)+g\left(x_{i} ; \gamma\right) v_{i}
$$

where $f\left(x_{i} ; \beta\right)$ is the deterministic production function, reflecting the effects of input on the mean of output; $g\left(x_{i} ; \gamma\right)$ is the risk function (variance function), specifying the effects of input on the variance of output; $\gamma$ is a parameter vector of the risk function and $v_{i}$ is a stochastic and normally distributed error term that is independently and identically distributed as $N(0,1)$. Thus, this function exhibits heteroskedasticity (the variance of the error term is not constant but variable across the sample.). The effects of an input on the level and variance of an output can be different, since $E(y)=f(x)$ and $V(y)=g^{2}\left(x_{i} ; \gamma\right)$. The marginal production risk, defined as

$$
\frac{\partial \operatorname{var}(y)}{\partial x_{i}}=2 g\left(x_{i} ; \gamma\right) \frac{\partial g}{\partial x_{i}}
$$

can be positive, negative, or zero. With a positive (negative) marginal production risk, a risk-averse farmer uses less (more) of the specific input than the risk-neutral farmer, and the input is known as risk-increasing (decreasing) by this output [24].

Kumbhakar [21] suggested a flexible approach to incorporate the inefficiency term with the Just and Pope function, by which the determinants of inefficiency are also examined:

$$
y_{i}=f\left(x_{i} ; \beta\right)+g\left(x_{i} ; \gamma\right) v_{i}+q\left(z_{i} ; \delta\right) u_{i}
$$

where $q(z ; \delta)$ is the inefficiency function capturing the relationship between different socio-economic characteristics of farmers and technical inefficiency; $z$ is the vector of socio-economic characteristics; and $\delta$ is a vector of parameters to be estimated. This function corresponds to the general SFA model with heteroskedasticity in $v_{i}$ and $u_{i}$, i.e., $\sigma_{v i}^{2}=\exp \left(x_{i} ; \gamma\right)$ and $\sigma_{u i}^{2}=\exp \left(z_{i} ; \delta\right)$ [21].

A single-step maximum likelihood $(\mathrm{ML})$ procedure is used to estimate the parameters in Equation (5) by optimizing the following log-likelihood function:

$$
\begin{aligned}
\ln L=\text { constant } & -\frac{1}{2} \sum_{i} \ln \left[\exp \left(z_{i} ; \delta\right)+\exp \left(x_{i} ; \gamma\right)\right]+\sum_{i} \ln \Phi \frac{-\varepsilon_{i} \lambda_{i}}{\sqrt{\exp \left(z_{i} ; \delta\right)+\exp \left(x_{i} ; \gamma\right)}} \\
& -\frac{1}{2} \sum_{i} \frac{\varepsilon_{i}{ }^{2}}{\exp \left(z_{i} ; \delta\right)+\exp \left(x_{i} ; \gamma\right)}
\end{aligned}
$$


where $\varepsilon_{i}=v_{i}-u_{i}$ corresponds to $\lambda_{i}=\sqrt{\exp \left(z_{i} ; \delta\right)} / \sqrt{\exp \left(x_{i} ; \gamma\right)} ; \Phi$ represents the standard normal distribution. According to Jondrow et al. [25] technical inefficiency of each farm can be measured through the conditional distribution of $u_{i}$ given $\varepsilon_{i}$.

\subsection{Data Description}

The data used in this study is from a farm-level survey conducted in the Nanzhang, Xiangzhou, and Yicheng districts of Xiangyang city in the Hubei province of Central China. Xiangyang city is one of the ten major cultivation territories for summer grain in China. This territory has 5.9 million inhabitants, of which $32.7 \%$ are engaged in agriculture. The arable land area is 0.4 million ha and the cultivated area for rice farming is 0.19 million ha. Using $0.34 \%$ of the arable land in China, Xiangyang produces $1 \%$ of the total grain production of the country.

The data was collected using a multi-stage sampling design. In the first stage, three districts in the Xiangyang city, Nanzhang, Xiangzhou, and Yicheng, were selected purposely according to their relative importance in grain production. In the second stage, three towns were selected randomly from each purposively-selected district, and then three villages from each town were selected at random. Finally, ten farm households were randomly selected from each village, thus making a total sampling size of 270 farm households. However, only 231 households provided complete information for the summer rice cultivation during the cropping season of 2013.

Farm level data were collected using an interview schedule on various inputs and output quantities. The output (rice production) was measured in kilograms. The inputs were measured as: (1) cropped area in hectares; (2) seed costs in RMB yuan; (3) chemical fertilizers (nitrogen, phosphate, and potassium) in kilograms; (4) pesticide costs in RMB yuan; (5) labor inputs (family labor and hired labor) in man-days; and (6) machinery costs in RMB yuan. Two dummy variables for the Xiangzhou and Yicheng are included to capture the variation in other factors that systematically differ between districts. The descriptive statistics of the inputs and output variables are presented in Table 1.

Table 1. Descriptive statistics of variables used in the production, risk, and inefficiency functions.

\begin{tabular}{|c|c|c|c|c|c|c|c|c|}
\hline \multirow[t]{2}{*}{ Variable } & \multicolumn{4}{|c|}{ Continuous Variables } & \multicolumn{4}{|c|}{$\begin{array}{l}\text { Proportion of Farmers with } \\
\text { Dummy Variables }\end{array}$} \\
\hline & Mean & S.D. & Min. & Max. & 0 & 1 & 2 & 3 \\
\hline Output & & & & & - & - & - & - \\
\hline Rice production $(\mathrm{kg})$ & 4234.09 & 7635.50 & 140.00 & $93,503.00$ & - & - & - & - \\
\hline Inputs & & & & & - & - & - & - \\
\hline Cropped area (ha) & 0.56 & 0.90 & 0.02 & 10.20 & - & - & - & - \\
\hline Seed (RMB yuan) & 802.18 & 1020.50 & 20.00 & 7874.00 & - & - & - & - \\
\hline Fertilizer(NPK) (kg) & 172.65 & 253.18 & 5.00 & 2683.00 & - & - & - & - \\
\hline Pesticide (RMB yuan) & 651.45 & 950.32 & 10.00 & 8497.00 & - & - & - & - \\
\hline Labor (man-days) & 39.15 & 41.36 & 4.00 & 263.00 & - & - & - & - \\
\hline Machinery (RMB yuan) & 1202.16 & 1558.51 & 10.00 & 9899.00 & - & - & - & - \\
\hline Environmental factors & - & - & - & - & - & - & - & - \\
\hline $\begin{array}{c}\text { Soil quality } \\
(1=\text { poor, } 2=\text { medium, } 3=\text { good })\end{array}$ & - & - & - & - & - & 7.79 & 58.01 & 45.83 \\
\hline Weather events $(0=$ no, $1=$ yes $)$ & - & - & - & - & 56.71 & 43.29 & - & - \\
\hline $\begin{array}{c}\text { Xiangzhou } \\
(1=\text { if the household lives in Xiangzhou })\end{array}$ & - & - & - & - & 33.77 & 66.23 & - & - \\
\hline $\begin{array}{c}\text { Yicheng } \\
\text { (1 = if the household lives in Yicheng) }\end{array}$ & - & - & - & - & 35.50 & 64.50 & - & - \\
\hline \multicolumn{9}{|l|}{ Managerial factors } \\
\hline Farmer's age (years) & 52.07 & 9.67 & 27.00 & 79.00 & - & - & - & - \\
\hline $\begin{array}{l}\text { Female ratio (the percentage of women } \\
\text { among the workers) }\end{array}$ & 43.50 & 11.71 & 0.00 & 87.09 & - & - & - & - \\
\hline
\end{tabular}


Table 1. Cont.

\begin{tabular}{cccccccc}
\hline \multirow{2}{*}{ Variable } & \multicolumn{3}{c}{ Continuous Variables } & & \multicolumn{3}{c}{ Proportion of Farmers with } \\
Dummy Variables
\end{tabular}

Table 1 also presents the summary statistics of the variables used in the risk function and inefficiency function. In addition to the input variables, two variables are specified to capture the effects of environmental characteristics on production risk, i.e., soil quality and weather events. We found that only $7.79 \%$ of the rice farms have relatively poor soil quality, while $58.01 \%$ and $45.83 \%$ of farms have medium and good soil quality, respectively. Moreover, $43.29 \%$ of the rice farms experienced floods and/or droughts during the crop season. Among the variables used in the inefficiency function, farmers' ages range from 27 to 79 years, with an average of 52 years. The average ratio of females to males among the workers is $43.50 \%$. Additionally, the average education is eight years, ranging from $0-16$ years. In our sample, $46.75 \%$ of rice farmers did not have access to extension services, while $53.25 \%$ received technological advices and/or trainings. With the development of non-farm economies in rural areas, a large proportion $(83.12 \%)$ of farmers had alternative sources of income. We find that $56.28 \%$ of the surveyed rice farmers perceived the negative effects of the excess application of agricultural chemicals on environment. The scale of cultivated farmland in the sample areas is extremely small. After categorizing the farmers according to their farm size, we find that $39.4 \%$ are small farms (less than 0.2 hectares), $29 \%$ are medium farms (between 0.2 and 0.5 hectares) and 31.6\% are large farms (greater than 0.5 hectares).

\subsection{Empirical Model Specification and Estimation}

Following previous studies (e.g., Reinhard et al. [26] Karagiannis et al. [27]), the stochastic frontier production function (Equation (5)) is specified using the translog functional form is:

$$
\ln y_{i}=\beta_{0}+\sum_{j=1}^{j} \ln x_{i j}+\frac{1}{2}\left(\sum_{j=1}^{j} \sum_{k=1}^{k} \beta_{j k} \ln x_{i j} \ln x_{i k}\right)+v_{i}-u_{i}
$$

where $y_{i}$ is the level of rice production; $x_{i j}$ are vectors of inputs (cultivated area, seed, fertilizer, pesticide, labor, and machinery) and $v_{i}$ and $u_{i}$ are the same to those specified in Equation (1). The risk function and the inefficiency function are specified as follows, respectively:

$$
\begin{aligned}
& \sigma_{v}^{2}=g\left(\prod_{j=1}^{6} x_{j}^{\gamma_{j}}\right) \\
& u_{i}=q\left(\sum_{i=1}^{i} \delta_{i} Z_{i}\right)
\end{aligned}
$$


where $x_{j}$ refers to the variables that are hypothesized to explain the production risk or variance function-the six input variables and two environmental characteristics (weather events and soil quality); $Z_{i}$ is vector of farm and household characteristics that possibly affect farmer's managerial capacity. The parameters of the stochastic frontier production function with a flexible risk specification, i.e., Equations (7)-(9), were estimated simultaneously in a single stage using the maximum likelihood estimator.

\section{Estimation Results and Discussion}

The results of estimated parameters for Equations (7)-(9) are reported in Table 2. Two models are estimated, an unrestricted variance model that incorporates the risk function and technical inefficiency and a restricted variance model without the risk function. Based on the likelihood ratio test for model specification, the restricted risk function is rejected in favor of the unrestricted risk function at the $1 \%$ level of significance. Both the null hypotheses that the Cobb-Douglas specification is preferred over the translog specification and the technical inefficiency effect is absent in the surveyed rice farms are rejected at the $1 \%$ level of significance. Thus, we mainly discuss the results estimated by the unrestricted variance model.

Table 2. Estimation results.

\begin{tabular}{|c|c|c|c|c|}
\hline \multirow{2}{*}{ Variable } & \multicolumn{2}{|c|}{ Unrestricted Risk Function } & \multicolumn{2}{|c|}{ Restricted Risk Function } \\
\hline & Coefficient & Std.err. & Coefficient & Std.err. \\
\hline \multicolumn{5}{|c|}{ Deterministic function } \\
\hline Ln area & $6.153^{* * *}$ & 1.227 & $5.217^{* * *}$ & 1.308 \\
\hline Ln seed & -0.629 & 0.641 & -0.371 & 0.796 \\
\hline Ln fertilizer & -0.354 & 0.759 & -0.209 & 0.813 \\
\hline Ln pesticide & $-1.723^{* * *}$ & 0.517 & $-1.554^{* * *}$ & 0.493 \\
\hline Ln labor & 0.681 & 0.629 & $1.076^{* *}$ & 0.430 \\
\hline Ln machinery & $-2.537^{* * *}$ & 0.891 & $-2.617^{* * *}$ & 0.711 \\
\hline Ln area $\times$ area & $0.439 * * *$ & 0.085 & $0.395^{* * *}$ & 0.130 \\
\hline Ln area $\times$ seed & $-0.187^{*}$ & 0.109 & -0.151 & 0.129 \\
\hline Ln area $\times$ fertilizer & -0.017 & 0.116 & -0.005 & 0.103 \\
\hline Ln area $\times$ pesticide & $-0.251^{* * *}$ & 0.047 & $-0.231^{* * *}$ & 0.060 \\
\hline Ln area $\times$ labor & 0.085 & 0.071 & $0.180 * *$ & 0.077 \\
\hline Ln area $\times$ machinery & $-0.392^{* * *}$ & 0.103 & $-0.401^{* * *}$ & 0.125 \\
\hline Ln seed $\times$ seed & 0.047 & 0.041 & 0.060 & 0.053 \\
\hline Ln seed $\times$ fertilizer & 0.081 & 0.070 & 0.049 & 0.071 \\
\hline Ln seed $\times$ pesticide & $-0.112^{* * *}$ & 0.034 & $-0.110^{* * *}$ & 0.036 \\
\hline Ln seed $\times$ labor & $-0.139 * *$ & 0.048 & $-0.190^{* * *}$ & 0.063 \\
\hline Ln seed $\times$ machinery & 0.078 & 0.055 & $0.108^{* *}$ & 0.059 \\
\hline Ln fertilizer $\times$ fertilizer & $-0.141^{* * *}$ & 0.037 & $-0.114 * *$ & 0.061 \\
\hline Ln fertilizer $\times$ pesticide & 0.019 & 0.022 & 0.047 & 0.038 \\
\hline Ln fertilizer $\times$ labor & 0.051 & 0.064 & 0.105 & 0.073 \\
\hline Ln fertilizer $\times$ machinery & 0.117 & 0.083 & 0.061 & 0.102 \\
\hline Ln pesticide $\times$ pesticide & $0.072^{* * *}$ & 0.018 & $0.079 * * *$ & 0.030 \\
\hline Ln pesticide $\times$ labor & $0.115^{* * *}$ & 0.023 & $0.107^{* * *}$ & 0.034 \\
\hline Ln pesticide $\times$ machinery & $0.110^{* * *}$ & 0.036 & $0.089 * *$ & 0.038 \\
\hline Ln labor $\times$ labor & $-0.125^{* * *}$ & 0.029 & $-0.131^{* * *}$ & 0.030 \\
\hline Ln labor $\times$ machinery & 0.030 & 0.041 & -0.032 & 0.029 \\
\hline Ln machinery $\times$ machinery & 0.035 & 0.041 & $0.084^{* *}$ & 0.034 \\
\hline Xiangzhou & 0.102 & 0.081 & 0.134 & 0.109 \\
\hline Yicheng & 0.254 & 0.197 & 0.236 & 0.201 \\
\hline Constant & $25.168^{* * *}$ & 4.327 & $23.509^{* * *}$ & 6.938 \\
\hline
\end{tabular}


Table 2. Cont.

\begin{tabular}{|c|c|c|c|c|}
\hline \multirow{2}{*}{ Variable } & \multicolumn{2}{|c|}{ Unrestricted Risk Function } & \multicolumn{2}{|c|}{ Restricted Risk Function } \\
\hline & Coefficient & Std.err. & Coefficient & Std.err. \\
\hline \multicolumn{5}{|c|}{ Risk function } \\
\hline Ln area & -2.031 & 1.572 & - & - \\
\hline Ln seed & -0.517 & 0.634 & - & - \\
\hline Ln fertilizer & -0.496 & 0.753 & - & - \\
\hline Ln pesticide & 0.857 & 0.501 & - & - \\
\hline Ln labor & $-1.593 * * *$ & 0.478 & - & - \\
\hline Ln machinery & $2.607^{* *}$ & 1.089 & - & - \\
\hline Soil quality & $-1.105^{* * *}$ & 0.381 & - & - \\
\hline Weather events & 0.504 & 0.737 & - & - \\
\hline \multicolumn{5}{|c|}{ Inefficiency function } \\
\hline Age & $-0.033 * * *$ & 0.010 & $-0.025^{* *}$ & 0.012 \\
\hline Female ratio & $0.019 *$ & 0.011 & $0.015^{*}$ & 0.008 \\
\hline Education & -0.026 & 0.031 & -0.051 & 0.047 \\
\hline Extension service & $-0.517 *$ & 0.291 & $-0.705^{* * *}$ & 0.232 \\
\hline Off-farm income & $-0.892^{* *}$ & 0.403 & -0.496 & 0.380 \\
\hline Credit access & -0.305 & 0.367 & -0.237 & 0.359 \\
\hline Environmental awareness & -0.451 & 0.304 & -0.252 & 0.301 \\
\hline Farm size_medium & -0.251 & 0.419 & -0.491 & 0.370 \\
\hline Farm size_large & $-0.718^{*}$ & 0.386 & $-1.205^{* * *}$ & 0.364 \\
\hline Log-likelihood & \multicolumn{2}{|c|}{101.29} & \multicolumn{2}{|c|}{87.03} \\
\hline
\end{tabular}

Since the estimated parameters in Table 2 are not directly interpretable, the output production elasticities regarding all inputs are computed and presented in Table 3. The elasticities' signs on cultivated area, fertilizer, and labor are positive. This implies that, holding all else constant, an increase in cultivated area, fertilizer, and labor would increase rice output. On average, output is more responsive to a change in cultivated area (1.419) relative to a change in fertilizer (0.581) and labor (0.359); those results are consistent with those generated from the restricted function. However, the elasticities of seed $(-0.357)$, pesticide $(-0.362)$ and machinery $(-0.136)$ are negative; this may suggest that, on average, the use of these three inputs has already reached its optimal level.

Table 3. Elasticity and returns to scale.

\begin{tabular}{ccc}
\hline Variables & Unrestricted Risk Function & Restricted Risk Function \\
\hline Area & 1.419 & 1.267 \\
Seed & -0.357 & -0.304 \\
Fertilizer & 0.581 & 0.438 \\
Pesticide & -0.362 & -0.330 \\
Labor & 0.359 & 0.321 \\
Machinery & -0.136 & -0.382 \\
Returns to scale & 1.504 & 1.010 \\
\hline
\end{tabular}

The sum of the elasticities for each farm represents their returns to scale (RTS). The average RTS for the total sample is 1.504, indicating that rice farms are operating under increasing returns to scale (IRTS). This implies that, holding all else constant, a $1 \%$ joint increase for all inputs will bring about more than a unit (1.504\%) increase in rice output. The RTS computed from the restricted risk function is $1.010 \%$. However, about $13 \%$ of the farms are found to operate under decreasing returns to scale (DRTS) while the remaining $87 \%$ are operating under IRTS. This implies that a majority of the rice farms could benefit by expanding their scale of operation. 
Results from the risk function in Table 2 show that the coefficient of cultivated area is negative and insignificant, providing weak evidence that larger cultivated area leads to decreased yield variability (production risk). The coefficients for both seed and fertilizer are found to have the risk-reducing effects on rice farming but also not statistically significant.

Contrary to a priori expectations, pesticides do not have a risk-reducing effect for rice farming; simply, they have no effects at all. At the $1 \%$ significance level, increased labor use is found to have a risk-reducing effect. This is consistent with our expectations, since the rice farms in the surveyed region are highly fragmented and, therefore, heavily dependent on labor, especially in the period of planting rice seedlings. Machinery was expected to have a risk-reducing effect, since the application of farm machinery could shorten the harvesting period and the exposure time to an uncertain environment [20,28]. However, the empirical results suggest that a higher use of machinery increases rice production variability. A possible explanation for this is that, except for rice seedling and field management, like fertilization, the tillage and harvesting stages of rice cultivation in the survey area are almost all mechanized, which make the farmers have to rely on temporary rental machinery. The dependence on machinery in peak periods may, in turn, increase production risks, particularly when the availability of rental services is too low.

In accordance with our expectations, good soil quality is found to exhibit a significantly stabilizing effect on rice production. This is consistent with the findings in previous literature that better quality soils can supply better nutrient to crops and, hence, can achieve more stable rice production compared with poorer soils $[24,29]$. In contrast, weather events, like drought and flood, have a risk-increasing effect on output. Although the effect is statistically insignificant, the result provides weak evidence that the existing farm infrastructure is not sufficient to enable farmers to better mitigate against weather events.

Table 4 presents the TE estimates derived from both the unrestricted and restricted variance models. The TE scores for the rice farms when the risk component is included range from $37 \%$ to $99 \%$ with an average score of $84 \%$, while the TE scores when the risk component is excluded range from $27 \%$ to $99 \%$, with an average of $79 \%$.The average TE scores suggest that a $16 \%$ and $21 \%$ increase of rice output could be achieved by improving technical management at the existing input levels use. Additionally, the difference of TE scores for the two methods suggests that TE is underestimated when the risk component is excluded. However, the Spearman rank test shows that both estimates are highly correlated with a correlation coefficient of 0.913 and significant at the $1 \%$ significance level. Comparisons of the different farm size groups indicate that on average large farms have high TE scores ( $87 \%$ and $85 \%$ ), relative to the medium farms ( $84 \%$ and $80 \%)$ and small farms $(83 \%$ and $78 \%$ ) under both the unrestricted and restricted models. The non-parametric Kruskal-Wallis (K-W) test indicates that this difference is significant at $1 \%$ significance level, implying that larger rice farms are more efficient than small farms in the sampled region.

Table 4. Frequency distribution of technical efficiency by farm size.

\begin{tabular}{|c|c|c|c|c|c|c|c|c|}
\hline \multirow{2}{*}{$\begin{array}{l}\text { Efficiency } \\
\text { Range }\end{array}$} & \multicolumn{2}{|c|}{ All } & \multicolumn{2}{|c|}{ Small ( $\leqslant 0.2$ ha) } & \multicolumn{2}{|c|}{ Medium (0.2 0.5 ha) } & \multicolumn{2}{|c|}{ Large (>0.5 ha) } \\
\hline & Unrestricted & Restricted & Unrestricted & Restricted & Unrestricted & Restricted & Unrestricted & Restricted \\
\hline$<30$ & 0 & 1 & 0 & 1 & 0 & 0 & 0 & 0 \\
\hline $30-40$ & 3 & 5 & 1 & 1 & 0 & 2 & 2 & 2 \\
\hline $40-50$ & 2 & 4 & 0 & 2 & 1 & 2 & 1 & 0 \\
\hline $50-60$ & 4 & 20 & 2 & 12 & 2 & 6 & 0 & 2 \\
\hline $60-70$ & 18 & 19 & 8 & 11 & 8 & 5 & 2 & 3 \\
\hline $70-80$ & 31 & 45 & 13 & 22 & 10 & 17 & 8 & 6 \\
\hline $80-90$ & 68 & 44 & 34 & 16 & 21 & 12 & 13 & 16 \\
\hline $90-100$ & 105 & 93 & 33 & 26 & 25 & 23 & 47 & 44 \\
\hline Mean & 0.84 & 0.79 & 0.83 & 0.78 & 0.84 & 0.80 & 0.87 & 0.85 \\
\hline Std. Dev. & 0.13 & 0.15 & 0.12 & 0.19 & 0.11 & 0.13 & 0.12 & $\mathrm{e}$ \\
\hline Minimum & 0.37 & 0.27 & 0.38 & 0.27 & 0.48 & 0.37 & 0.37 & 0.36 \\
\hline Maximum & 0.99 & 0.99 & 0.99 & 0.98 & 0.99 & 0.99 & 0.99 & 0.98 \\
\hline Observations & \multicolumn{2}{|c|}{231} & \multicolumn{2}{|c|}{91} & \multicolumn{2}{|c|}{67} & \multicolumn{2}{|c|}{73} \\
\hline
\end{tabular}


With respect to the determinants of inefficiency, most of the estimated coefficients of the investigated variables confirm to a priori expectations about their influence on inefficiency levels and are qualitatively consistent between the estimated models. A negative sign on the parameters implies positive influences on TE. The results in Table 2 indicate that farmer's age has a significantly positive effect on TE. Several studies suggest that older farmers are more experienced in farming which is helpful to improve efficiency $[27,30,31]$. Furthermore, the strict physical demands of crop production on labor could be partially offset by wide use of modern farm machinery. However, other studies have found that older farmers are more reluctant to adopt new farm technologies and, thus, remain technically inefficient $[17,32,33]$. The results clearly illustrate that having a higher proportion of female to male workers leads to less technical efficiency. These findings are similar to those of $\mathrm{Li}$ and Sicular [15] for efficiency in crop production in Liaoning Province of China.

As expected, education and extension services exert a positive influence (education is positive but insignificant, while extension services is significantly positive) on TE. These results are in agreement with the general belief that improvement of human capital enables farmers to use farm resources more efficiently [34]. As suggested in the literature, educated farmers often perform better in farm management and are receptive to new technologies compared to their less educated counterparts, hence the high efficiency level $[35,36]$. The impact of extension services on TE supports, a priori, that the farmers who sought and/or received more extension services, like technological advice and training programs, often exhibit higher efficiency in farming compared to those who have less or no contact with the extension staff $[27,33,37]$.

Off-farm income is found to have a positive impact on farmer's efficiency (the coefficient is only significant in the unrestricted model). In general, alternative income resources can help farmers to make necessary and timely investments, such as optimal inputs allocation and utilization [38,39]. Similarly, farmers who used credit are more technically efficient than those who did not, since credit access helps relaxing farmer's budget constraint which could enable them to have enough liquidity to purchase and apply input resources efficiently [40,41].

Environmental awareness has a positive impact on TE but not significant. We find that only larger farms have a positive and significant association with technical efficiency, further confirming the statistical analysis discussed above.

\section{Conclusions}

This study investigated the presence of production risk and technical inefficiency for a sample of 231 rice farms in the Xiangyang city of China. The results indicate that yield variability (production risk) respond differently to different input use and production gaps from the potential maximum output can be attributed to technical inefficiency in production.

We find that among the inputs, only labor and machinery have significant risk effects on rice production; labor has a risk-reducing effect, while machinery has risk-increasing effect. This implies that excessive dependence on farming machinery may cause significant variation of rice production in the sample area. Moreover, good soil quality significantly reduces production risk. The estimated results on output elasticities indicate that rice production is highly responsive to cultivated area than fertilizer and labor, and is least responsive to pesticide, seed, and machinery. This implies that the usage of pesticide, seed, and machinery is more than optimal given the scale of production. The results also indicate that most of the surveyed rice farms operate under increasing returns to scale, suggesting that, on average, farms would benefit by expanding their scale of operation.

The average technical efficiency for the rice farms is $84 \%$, implying that rice farmers in Xiangyang can potentially increase their output by $16 \%$ simply through adjusting their technical and managerial practices, without increasing the current level of inputs. We also find that larger farms are more technically efficient than the smaller farms. The estimated inefficiency model shows that farmer's age, extension services, off-farm income, and farm size significantly and positively influenced technical efficiency, while the percentage of women among the workers significantly and negatively affected technical efficiencies. 
Based on the results above, the implication of our results is that rice productivity can be improved by an appropriate choice of input combinations and elimination of mistakes in the production process. Farmers have to give special attention to managing those inputs that have a risk-increasing effect on output variability. For example, in our study area, increased usage of machinery would not only decrease rice output but also increase production variability (production risk). Thus, policies should give priority to enhancing research and providing more information to farmers for the purpose of the improvement of management practices of these inputs. In contrast, good soil quality could help to achieve a more stable rice production. Thus, policies that support soil improvement programs can reduce production risk. In particular, within the context of constrained resources and environmental pressure, providing better extension services to improve farmer's uptake of existing production technologies and raise their environmental awareness, loosening liquidity constraints facing farmers through alternative sources of income, would help to achieve higher efficiency in production.

Acknowledgments: We gratefully acknowledge the financial support from the National Social Science Foundation of China (No. 13AGL004; No. 16CGL038), the Fundamental Research Funds for the Central Universities (No. 2662015QD052), and the China Scholarship Council (No. 201306760028).

Author Contributions: Zhihai Yang and Amin Mugera designed the research. Zhihai Yang collected data. Zhihai Yang and Amin Mugera analyzed the data. Zhihai Yang, Amin Mugera and Fan Zhang drafted and revised the paper. All authors read and approved the final manuscript.

Conflicts of Interest: The authors declare no conflict of interest.

\section{References}

1. Liu, G.; Zhang, L.; Zhang, Q.; Zipporah, M. The response of grain production to changes in quantity and quality of cropland in Yangtze River Delta, China. J. Sci. Food Agric. 2015, 95, 480-489. [CrossRef] [PubMed]

2. FAO. The State of Food Insecurity in the World 2008; FAO: Rome, Italy, 2008.

3. FAO. FAO Statistical Yearbook 2009; FAO: Rome, Italy, 2009.

4. NBS. China Agriculture Statistical Yearbook; China Agriculture Press: Beijing, China, 2013. (In Chinese)

5. You, L.Z. A tale of two countries: Spatial and temporal patterns of rice productivity in China and Brazil. China Econ. Rev. 2012, 23, 690-703. [CrossRef]

6. Khan, S.; Hanjra, M.A.; Mu, J. Water management and crop production for food security in China: A review. Agric. Water Manag. 2009, 96, 349-360. [CrossRef]

7. Tao, F.; Yokozawa, M.; Liu, J.; Zhang, Z. Climate change, land use change, and China's food security in the twenty-first century: An integrated perspective. Clim. Chang. 2009, 93, 433-445. [CrossRef]

8. Xu, Z.; Yu, Z.; Zhao, J. Theory and application for the promotion of wheat production in China: Past, present and future. J. Sci. Food Agric. 2013, 93, 2339-2350. [CrossRef] [PubMed]

9. McBeath, J.; McBeath, J.H. Environmental stressors and food security in China. J. Chin. Political Sci. 2009, 14, 49-80. [CrossRef]

10. Piao, S.; Ciais, P.; Huang, Y.; Shen, Z.; Peng, S.; Li, J.; Zhou, L.; Liu, H.; Ma, Y.; Ding, Y. The impacts of climate change on water resources and agriculture in China. Nature 2010, 467, 43-51. [CrossRef] [PubMed]

11. Zhou, D.; An, P.; Pan, Z.; Zhang, F. Arable land use intensity change in China from 1985 to 2005: Evidence from integrated cropping systems and agro economic analysis. J. Agric. Sci. 2012, 150, 179-190. [CrossRef]

12. Wang, X.; Hockmann, H.; Bai, J. Technical Efficiency and Producers' Individual Technology: Accounting for Within and Between Regional Farm Heterogeneity. Can. J. Agric. Econ. 2012, 60, 561-576. [CrossRef]

13. Zhang, Y.; Wang, X.; Glauben, T.; Brümmer, B. The impact of land reallocation on technical efficiency: Evidence from China. Agric. Econ. 2011, 42, 495-507. [CrossRef]

14. Brümmer, B.; Glauben, T.; Lu, W. Policy reform and productivity change in Chinese agriculture: A distance function approach. J. Dev. Econ. 2006, 81, 61-79. [CrossRef]

15. Li, M.; Sicular, T. Aging of the labor force and technical efficiency in crop production: Evidence from Liaoning province, China. China Agric. Econ. Rev. 2013, 5, 342-359. [CrossRef]

16. Ma, L.; Feng, S.; Reidsma, P.; Qu, F.; Heerink, N. Identifying entry points to improve fertilizer use efficiency in Taihu Basin, China. Land Use Policy 2014, 37, 52-59. [CrossRef]

17. Villano, R.; Fleming, E. Technical Inefficiency and Production Risk in Rice Farming: Evidence from Central Luzon Philippines. Asian Econ. J. 2006, 20, 29-46. [CrossRef] 
18. Tveteras, R.; Flaten, O.; Lien, G. Production risk in multi-output industries: Estimates from Norwegian dairy farms. Appl. Econ. 2011, 43, 4403-4414. [CrossRef]

19. Bokusheva, R.; Hockmann, H. Production risk and technical inefficiency in Russian agriculture. Eur. Rev. Agric. Econ. 2006, 33, 93-118. [CrossRef]

20. Just, R.E.; Pope, R.D. Stochastic specification of production functions and economic implications. J. Econom. 1978, 7, 67-86. [CrossRef]

21. Kumbhakar, S.C. Specification and estimation of production risk, risk preferences and technical efficiency. Am. J. Agric. Econ. 2002, 84, 8-22. [CrossRef]

22. Aigner, D.; Lovell, C.A.; Schmidt, P. Formulation and estimation of stochastic frontier production function models. J. Econom. 1977, 6, 21-37. [CrossRef]

23. Meeusen, W.; van den Broeck, J. Efficiency estimation from Cobb-Douglas production functions with composed error. Int. Econ. Rev. 1977, 18, 435-444. [CrossRef]

24. Tiedemann, T.; Latacz-Lohmann, U. Production Risk and Technical Efficiency in Organic and Conventional Agriculture-The Case of Arable Farms in Germany. J. Agric. Econ. 2013, 64, 73-96. [CrossRef]

25. Jondrow, J.; Knox Lovell, C.; Materov, I.S.; Schmidt, P. On the estimation of technical inefficiency in the stochastic frontier production function model. J. Econom. 1982, 19, 233-238. [CrossRef]

26. Reinhard, S.; Lovell, C.K.; Thijssen, G. Econometric estimation of technical and environmental efficiency: An application to Dutch dairy farms. Am. J. Agric. Econ. 1999, 81, 44-60. [CrossRef]

27. Karagiannis, G.; Tzouvelekas, V.; Xepapadeas, A. Measuring irrigation water efficiency with a stochastic production frontier. Environ. Resour. Econ. 2003, 26, 57-72. [CrossRef]

28. Gardebroek, C.; Chavez, M.D.; Lansink, A.O. Analysing Production Technology and Risk in Organic and Conventional Dutch Arable Farming using Panel Data. J. Agric. Econ. 2010, 61, 60-75. [CrossRef]

29. Chang, H.H.; Wen, F.I. Off-farm work, technical efficiency, and rice production risk in Taiwan. Agric. Econ. 2011, 42, 269-278. [CrossRef]

30. Mariano, M.J.; Villano, R.; Fleming, E. Technical Efficiency of Rice Farms in Different Agroclimatic Zones in the Philippines: An Application of a Stochastic Metafrontier Model. Asian Econ. J. 2011, 25, 245-269. [CrossRef]

31. Külekçi, M. Technical efficiency analysis for oilseed sunflower farms: A case study in Erzurum, Turkey. J. Sci. Food Agric. 2010, 90, 1508-1512. [CrossRef] [PubMed]

32. Speelman, S.; D'Haese, M.; Buysse, J.; D'Haese, L. A measure for the efficiency of water use and its determinants, a case study of small-scale irrigation schemes in North-West Province, South Africa. Agric. Syst. 2008, 98, 31-39. [CrossRef]

33. Watto, M.A.; Mugera, A. Measuring efficiency of cotton cultivation in Pakistan: A restricted production frontier study. J. Sci. Food Agric. 2014, 94, 3038-3045. [CrossRef] [PubMed]

34. Watto, M.A.; Mugera, A.W. Efficiency of irrigation water application in sugarcane cultivation in Pakistan. J. Sci. Food Agric. 2015, 95, 1860-1867. [CrossRef] [PubMed]

35. Demircan, V.; Binici, T.; Zulauf, C.R. Assessing pure technical efficiency of dairy farms in Turkey. Agric. Econ. 2010, 56, 141-148.

36. Xu, H.Z.; Chen, T. Impact of farmers' differentiation on farmland-use efficiency: Evidence from household survey data in rural China. Agric. Econ. 2013, 59, 227-234.

37. Khan, H.; Ali, F. Measurement of productive efficiency of tomato growers in Peshawar, Pakistan. Agric. Econ. 2013, 59, 381-388.

38. Chavas, J.-P.; Petrie, R.; Roth, M. Farm household production efficiency: Evidence from the Gambia. Am. J. Agric. Econ. 2005, 87, 160-179. [CrossRef]

39. Oseni, G.; Winters, P. Rural nonfarm activities and agricultural crop production in Nigeria. Agric. Econ. 2009, 40, 189-201. [CrossRef]

40. Haji, J. Production efficiency of smallholders' vegetable-dominated mixed farming system in eastern Ethiopia: A non-parametric approach. J. Afr. Econom. 2007, 16, 1-27. [CrossRef]

41. Ogundari, K. Resource-productivity, allocative efficiency and determinants of technical efficiency of rainfed rice farmers: A guide for food security policy in Nigeria. Agric. Econ. 2008, 54, 224-233.

(c) 2016 by the authors; licensee MDPI, Basel, Switzerland. This article is an open access article distributed under the terms and conditions of the Creative Commons Attribution (CC-BY) license (http://creativecommons.org/licenses/by/4.0/). 